\title{
SURVEY KRITERIA STANDAR USAHA 7 LOKASI WISATA DI KABUPATEN MANGGARAI BARAT TAHUN 2019
}

\author{
Ernesta Leha1 , Daniel Wolo ${ }^{2 *}$, Ana S. Rahmawati ${ }^{3}$, Yohanes Y.W. Kean ${ }^{4}$ \\ 1,2,3,4Universitas Flores, Ende, Indonesia \\ *Penulis Koresponsensi, email: dewolochem@gmail.com
}

Received:02/02/2021

Revised:06/04/2021

Accepted:07/04/2021

\begin{abstract}
As one of the leading destinations, Labuan Bajo offers several natural tourist attractions that are no less interesting. However, some destinations do not yet have a tourism ecosystem management that can balance ethics, aesthetics, economy, and locality to create excellence in quality tourist destinations. The University of Flores' research team has conducted a survey of standard facilities or standard criteria in 7 tourist sites in the West Manggarai district. The seven locations include Tado Village, Melo Traditional Village, Padar Island, Komodo Island, Rangko Cave, Batu Cermin Cave, Senanggoang Lake. The survey conducted aims to capture tourist destinations from three aspects, namely product, service, and management. Based on the results of the survey that has been conducted, it can be said that: several standard facilities in 7 tourist destinations have not been met. Suggestions are given to the Regency Government and managers of tourist destinations in West Manggarai Regency to work together to procure existing facilities and facilities so that tourism objects in the 7 locations become more organized and advanced.
\end{abstract}

Keywords: Destination survey, Labuan Bajo, Komodo, Senanggoang Lake, Melo Village,

Abstrak. Sebagai salah satu destinasi utama, Labuan Bajo menawarkan beberapa atraksi wisata alam yang tidak kalah menarik. Namun beberapa destinasi belum memiliki tata kelola ekosistem pariwisata yang mampu menyeimbangkan etika, estetika, ekonomi serta lokalitas untuk menciptakan keunggulan destinasi wisata yang berkualitas. Tim Peneltian dari Universitas Flores telah melakukan survey terhadap fasilitas standar atau kriteria standar yang ada di 7 lokasi wisata kabupaten Manggarai Barat. Ketujuh lokasi itu antara lain Kampung Tado, Desa Adat Melo, Pulau Padar, Pulau Komodo, Gua Rangko, Gua Batu Cermin, Danau Senanggoang. Survey yang telah dilakukan bertujuan untuk memotret kondisi destinasi wisata dari tiga aspek yaitu produk, pekayanan dan pengelolaan. Berdasarkan hasil survey yang telah dilakukan dapat disimpulkan bahwa : belum terpenuhi beberapa fasilitas standar di 7 destinasi wisata. Saran yang diberikan kepada Pemerintah Kabupaten dan pengelola destinasi wisata di Kabupaten Manggarai Barat bekerja sama dalam pengadaan fasilitas dan memelihara fasilitas yang telah ada, sehingga objek pariwisata di 7 lokasi tersebut menjadi semakin tertata dan maju.

Kata Kunci: Survey destinasi, Labuan bajo, Komodo, Danau Senanggoang, Desa Melo

How to Cite: Leha, E., Wolo, D., Rahmawati, A. S. ., \& Kean, Y. Y. W. (2021). Survey Kriteria Standar Usaha 7 Lokasi Wisata di Kabupaten Manggarai Barat Tahun 2019. Mitra Mahajana: Jurnal Pengabdian Masyarakat,2(2), 105-116. https://doi.org/10.37478/mahajana.v2i2.820

\section{PENDAHULUAN}

Sampai saat ini, destinasi wisata Labuan Bajo masih menjadi alternatif pilihan kedua setelah Bali (Remmer, 2017) . Keunggulan pariwisata Labuan Bajo terletak pada keberadaan habitat reptil raksasa Komodo (Varanus Komodoensis). Pada tahun 1986, wilayah Komodo ditetapkan sebagai Taman Nasional Komodo dan pada tahun 2015 Labuan Bajo dikukuhkan sebagai destinasi snorkling terbaik kedua di dunia setelah Raja Ampat (Rufalzyh, 2017) Selain itu, di wilayah ini terdapat pula destinasi wisata lainnya seperti pink beach dan perairan laut dengan terumbu karangnya mempesona.

Keragaman detinasi wisata Labuan Bajo tidak perlu diperdebatkan lagi karena aspek obyek dan atraksi di wilayah ini merupakan representasi hampir seluruh mata rantai yang dibutuhkan wisatawan. Ketika labuan Bajo terpilih sebagai salah satu dari 10 destinasi tujuan wisata prioritas pada tahun 2016, ini berarti Labuan Bajo menjadi salah satu tulang punggung pariwisata nasional dan diharapkan target penerimaan dari sektor pariwisata di wilayah ini mengalami peningkatan (Rufalzyh, 2017). Namun hal ini tentu tidak mudah karena dibutuhkan dukungan dan kerjasama serta koordinasi yang terintegrasi dari seluruh stakeholder yang ada. Pada kegiatan ini MCSTO Universitas Flores telah melakukan survey terhadap fasilitas standar 
atau kriteria standar yang ada di 7 lokasi wisata kabupaten Manggarai Barat. Ketujuh lokasi itu antara lain Kampung Tado, Desa Adat Melo, Pulau Padar, Pulau Komodo, Gua Rangko, Gua Batu Cermin, Danau Senanggoang. Sebelum melakukan kegiatan survey, Tim Peneliti Universitas Flores telah melakukan rapat koordinasi dengan beberapa pihak seperti dinas Pariwisata dan pihak Swiss Contact. Hasil program kerja awal ini diharapkan menjadi titik awal untuk pembangunan pariwisata yang berkelanjutan di Labuan Bajo.

Salah satu persoalan utama yang mendominasi upaya pengembangan pariwisata berkelanjutan di Labuan Bajo adalah masalah sampah terutama sampah plastik yang bertebaran di hampir semua destinasi wisata terutama disepanjang pesisir pantai (Rachim \& Ginting, 2019) Rendahnya kesadaran masyarakat tentang kebersihan dan minimnya sarana tempat pembuangan sampah menyebabkan banyak destinasi wisata di Labuan Bajo tercemar sampah yang semakin lama makin memprihatinkan.

Persoalan kedua adalah limbah cair. Usaha hotel dan kuliner yang bertebaran di kota Labuan Bajo dan di lokasi destinasi wisata lainnya disekitar labuan Bajo. Selain itu belum adanya tata kelola ekosistem pariwisata yang mampu menyeimbangkan etika, estetika, ekonomi serta lokalitas untuk menciptakan keunggulan destinasi wisata yang berkualitas. Untuk itu perlu dirumuskan sebuah solusi yang tepat, efektif dan efisien agar keberlanjutan dari aspek ekonomi masyrakat lokal, dan lingkungan yang bersih dan sehat bisa tercapai.

Kegiatan survey kriteria standar usaha wisata di 7 destinasi wisata ini merupakan tahap awal dari program kerja MCSTO Universitas Flores di Manggarai Barat. Pembangunan destinasi wisata berkelanjutan dalam menawarkan keindahan alam, kekayaan budaya dan keramahtamahan layanan. Sedikit sekali sumber daya yang digunakan untuk menyokong kegiatan wisata tersebut. Oleh karena itu diperlukan pembangunan destinasi yang berkelanjutan sehingga akan mudah dikelola dalam waktu yang cukup lama bagi keberlangsungan masyarakat yang juga adalah penyangga destinasi tersebut. Survey dilaksanakan dengan mendatangi langsung lokasi, berdiskusi dengan pengelola wisata dan pengamatan terhadap fasilitas standar wisata yang ada di lokasi.

\section{METODE PELAKSANAAN}

Kegiatan pengabdian ini merupakan tahapan awal dari kajian pariwisata berkelanjutan di Labuan Bajo, Manggarai Barat. Untuk itu tim peneliti melakukan survey terhadap beberapa destinasi yang menjadi wisata penyokong pulau Komodo. Melalui survey ini tim peneliti mendapatkan gambaran kondisi awal dari setiap destinasi tersebut. Adapun langkah-langkah atau tahapan yang dilakukan adalah melalui koordinasi dengan instansi terkait dalam hal ini dinas pariwisata kabupaten Manggarai barat dan LSM yang bergerak alam bidang pengembangan pariwisata di manggarai Barat yaitu Swiss Contact. Setelah berkoordinasi dan mendapatkan gambaran dari stakeholder terkait, tim Universitas Flores kemudian melakukan survey dengan langsung turun ke lapangan atau lokasi destinasi. Waktu pelaksanaan Kegiatan survey dilaksanakan pada tanggal 10 - 15 April 2019. Adapun destinasi yang dijadikan objek survey adalah : (1) Pulau Komodo; (2) Pulau Padar; (3) Gua Rangko; (4)Gua Batu Cermin; (5) Danau Senanggoang; (6) Kampung Tado; (7) Desa Adat Melo.

Survey yang telah dilakukan bertujuan untuk memotret kondisi destinasi wisata dari tiga aspek yaitu produk, pekayanan dan pengelolaan. Adapun dari aspek produk akan dinilai unsur dan sub unsur yang tersedia seperti unsur petunjuk arah dengan dua sub unsur yaitu tersedia nama papan nama objek wisata dan tersedianya tanda arah menuju objek wisata. Hasil survey akan ditampilkan pada tabel di bagian hasil dan pembahasan.

\section{HASIL DAN PEMBAHASAN}

Manggarai Barat dengan Ibu Kota Labuan Bajo adalah salah satu kabupaten di pulau Flores dengan potensi wisata yang luar biasa. Bila dilihat dari tata letak geografis terbentang 


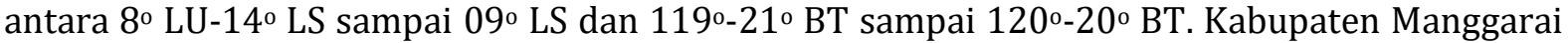
dipimpin seorang Bupati dengan jumlah penduduk 251.689 jiwa (NTT Dalam angka tahun 2015). Secara administrasi , terdiri atas 12 kecamatan, 227 desa dan 27 kelurahan. Sebanyak 23 desa secara geografis letak wilayah dikategorikan sebagai desa/daerah pantai/pesisir, sementara 98 desa lain merupakan desa bukan pesisir. Potensi wisata Manggarai Barat yang terkenal sampai ke mancanegara adalah Taman Nasional Komodo. Namun banyak juga destinasi wisata lainnya yang ada di wilayah manggarai Barat selain Pulau Komodo dan Padar seperti Gua Rangko, Gua Batu Cermin, Danau Senanggoang, kampung Tado, Desa adat Melo.

\section{Pulau Komodo}

Pulau Komodo merupakan salah satu pulau dalam lingkup Taman Nasional Komodo selain pulau Rinca, Padar, dan beberapa pulau kecil lainnya. Terletak di daerah administrasi Provinsi Nusa Tenggara Timur. Pada tahun 1980 taman nasional ini didirikan untuk melindungi komodo dan habitatnya. Disana terdapat 277 spesies hewam yang merupakan perpaduan hewan yang berasal dari Asia dan Australia, yang terdiri dari 32 spesies mamalia, 128 spesies burung, dan 37 spesies reptilia. Bersama dengan Komodo, setidaknya ada 25 spesies hewan darat dan burung termasuk termasuk hewan yang dilindungi, karena jumlahnya yang terbatas atau terbatasnya penyebaran hewan tersebut (Mustari et al., 2010)

Selain itu, di kawasan ini terdapat pula terumbu karang. Setidaknya terdapat 253 spesies karang pementuk terumbu yang ditemukan disana, dengan 1000 spesies ikan. Keindahan terumbu ini menarik minat wisatawan asing untuk berenang atau menyelam di perairan ini. Pulau-pulau ini aslinya adalah pulau vulkanis. Jumlah penduduk di wilayah ini kurang lebih 4000 jiwa. Pada tahun 1991 taman nasional ini diterima sebagai situs warisan dunia UNESCO. Pulau Komodo dapat dijangkau dengan boat trip selama 2 jam dari Labuan Bajo.

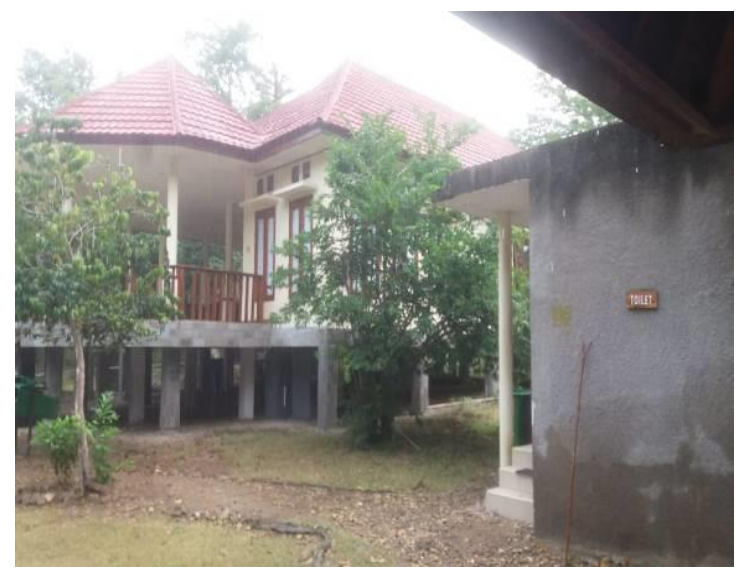

(i)

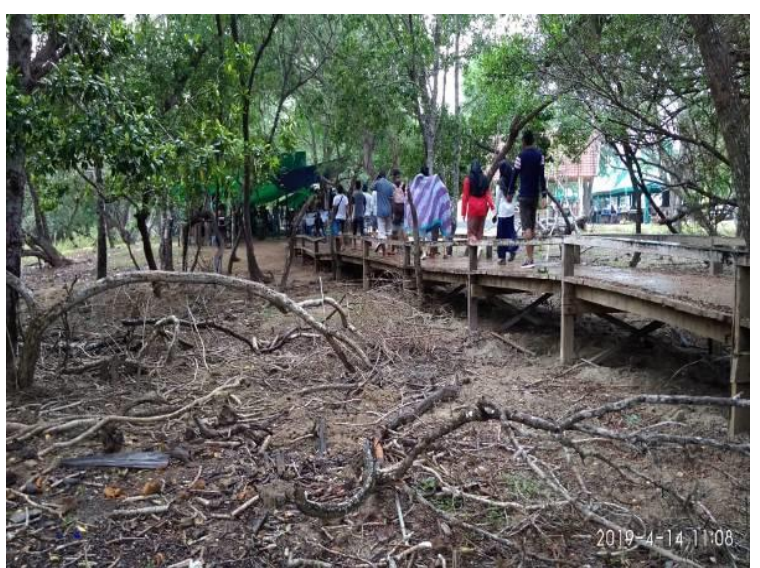

(ii)

Gambar 1. Fasilitas toilet umum di Pulau Komodo (i) dan Jalur masuk ke pos jaga pulau Komodo (ii)

\section{Pulau Padar}

Pulau Padar adalah Pulau ketiga terbesar di kawasan Taman Nasional Komodo, setelah Pulau Komodo dan Pulau Rinca. Pulau ini relatif lebih dekat ke pulau Rinca daripada Pulau Komodo, yang dipisahkan oleh selat Lintah. Pulau Padar tidak dihuni oleh ora (biawak komodo). Di sekitar tiga pulau ini terdapat tiga atau empat pulau kecil. Pulau Padar juga diterima sebagai situs warisan dunia UNESCO, karena berada dalam wilayah Taman Nasional Komodo, bersama dengan pulau Komodo, Pulau Rinca, dan Gili Motang (Yusni Wiarti, et al., 2017). Pulau yang gambarnya terpeta pada background foto pahlawan nasional di pecahan uang Rp. 50.000 keluaran 2016 ini merupakan spot favorit pengunjung untuk melakukan swa foto atau sekedar menikmati akan terlihat hijau di musim hujan dan kuning kecoklatan di musim kemarau. Butuh waktu sekitar 2- 
3 jam perjalanan dari Labuan Bajo menuju pulau ini. Sayang sekali kondisi toilet di pulau ini tidak bisa digunakan karena rusak dan mungkin karena ketiadaan air mengingat tidak ada sumber mata air di pulau ini. Selain itu akses trecking ke puncaknya belum dilengkapi pembatas pengaman sehingga pengunjung perlu berhatihati ketika mendaki.

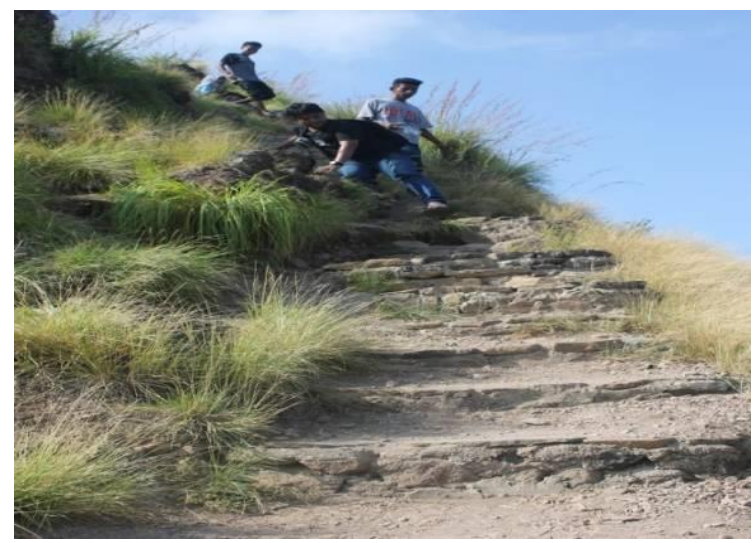

(i)

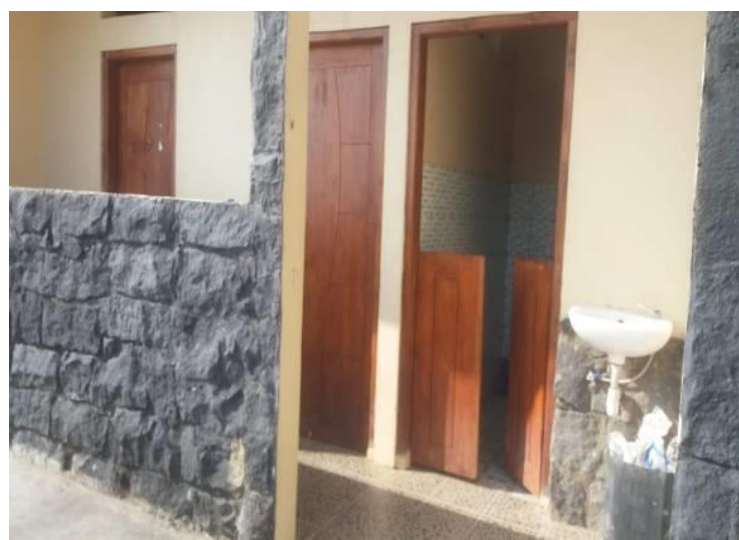

(ii)

Gambar 2. Jalur pendakian di puncak padar belum ada pembatas pengaman (i) dan salah satu fasilitas toilet umum di Pulau Padar (ii)

\section{Gua Rangko}

Gua Rangko terletak di desa Rangko, kecamatan Boleng, Kabupaten Manggarai Barat. Lokasi gua dapat dicapai dengan kendaraan bermotor selama 1 jam dari Labuan Bajo dan dilanjutkan dengan berjalan kaki menyusuri pantai. Keunikan gua yang juga dikenal dengan nama Gua Buaya ini adalah terdapatnya kolam jernih di dalam gua. Kondisi kolam yang tenang mengundang minat pengunjung untuk berenang. Namun demikian kadar garam di kolam gua tergolong tinggi (Suasapha et al., 2020) Secara geografis, lokasi gua tidak jauh dari laut. Ronggarongga atau celah dalam gua juga terhubung langsung ke laut. Fasilitas di destinasi ini masih sangat minim kalaupun ada sudah tidak terawat bahkan rusak. Misalnya papan penunjuk arah, akses kedalam gua juga cukup ekstrim karena harus melewati lorong gelap yang sempit dengan minim fasilitas pengaman. Beberapa keluhan juga disampaikan masyarakat kampung yang tinggal di sekitar gua rangko perihal beberapa wisatawan yang mengenakan pakaian renang yang minim dan lalu lalang melewati kampung mereka. Perlu koordinasi bersama antara pemda, LSM dan masyarakat agar bisa mencari solusi agar potensi wisata gua rangko ini bisa bermanfaat bagi masyarakat tanpa mengganggu adat kebiasaan masyarakat setempat.

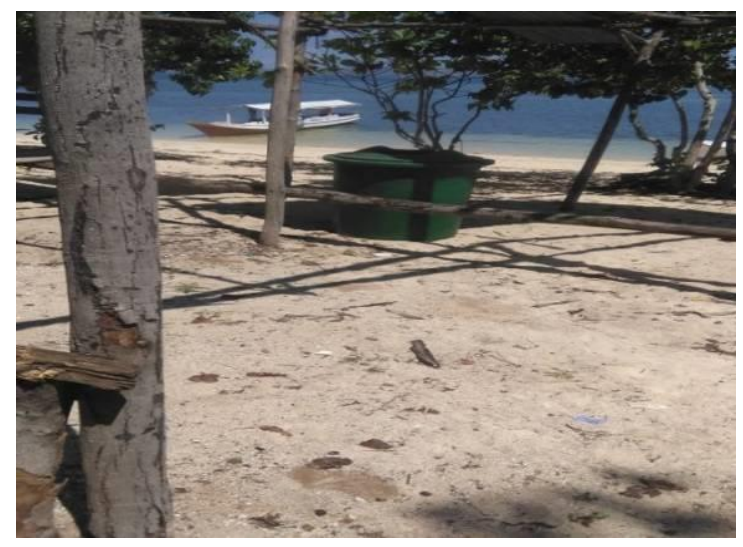

(i)

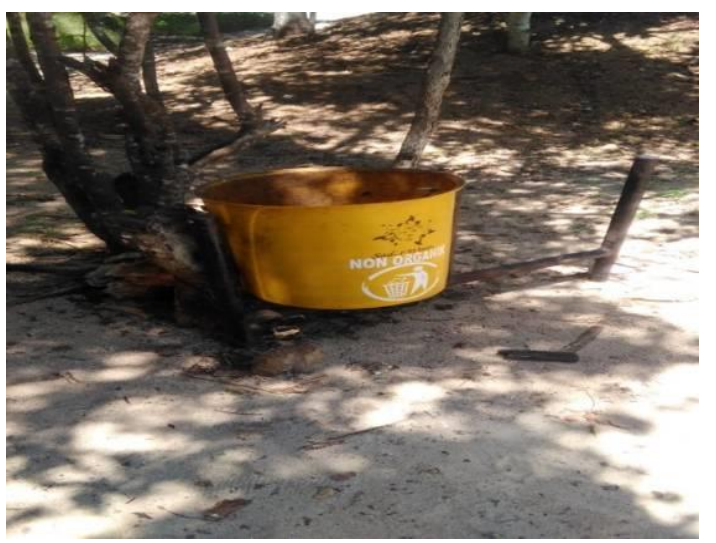

(ii)

Gambar 3. Shelter persinggahan wisatawan yang tidak memadai (i), kondisi Tempat sampah hanya ada satu buah di lokasi shelter 


\section{Gua Batu Cermin}

Gua Batu Cermin adalah adalah gua atau terowongan yang terdapat di bukit batu yang gelap di Labuan Bajo, Manggarai Barat, Flores, Nusa Tenggara Timur, Indonesia. Luas gua ini sekitar 19 hektar, dan tingginya sekitar 75 meter. Gua ini ditemukan oleh Theodore Verhoven seorang pastor Belanda sekaligus seorang arkeolog (Indayani \& Dewi, 2018). Gua tersebut ditemukan pada tahun 1951. Sinar matahari masuk ke gua mlalui dinding-dinding gua, dan memantulkan cahayanya di dinding batu sehingga merefleksikan cahaya kecil ke areal lain dalam gua sehingga terlihat seperti cermin. Stalagmit dan stalagtit dalam gua terlihat berkilauan saat disinari cahaya senter maupun cahaya matahari. Kilauan ini disebabkan oleh kandungan garam di dalam air yang menetes saat turun hujan. Hal inilah yang menyebabkan masyarakat sekitar gua ini dengan gua Batu Cermin. Fasilitas yang ada di Gua Batu Cermin bisa dikatakan sudah baik, kerena terdapat areak parkir yang luas, area perbelanjaan, lobby utama atau pusat informasi, pemandu dilengkapi dengan alat pengaman.

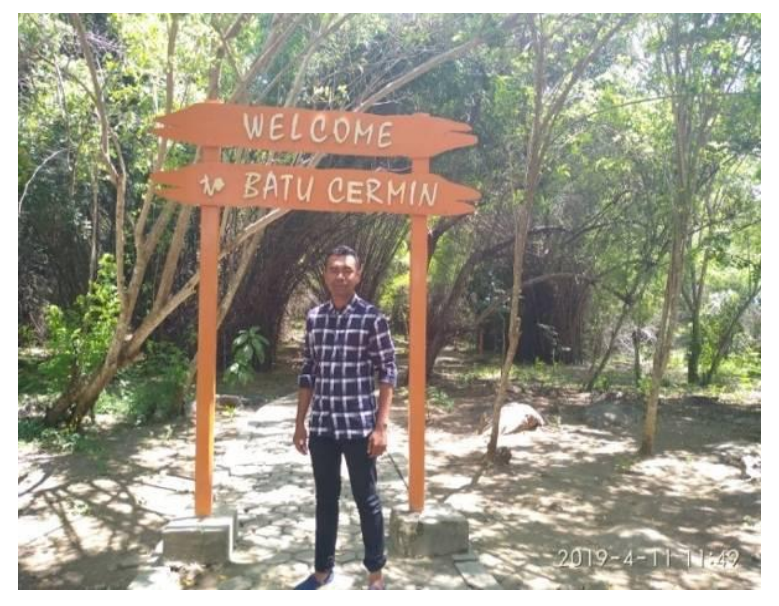

(i)

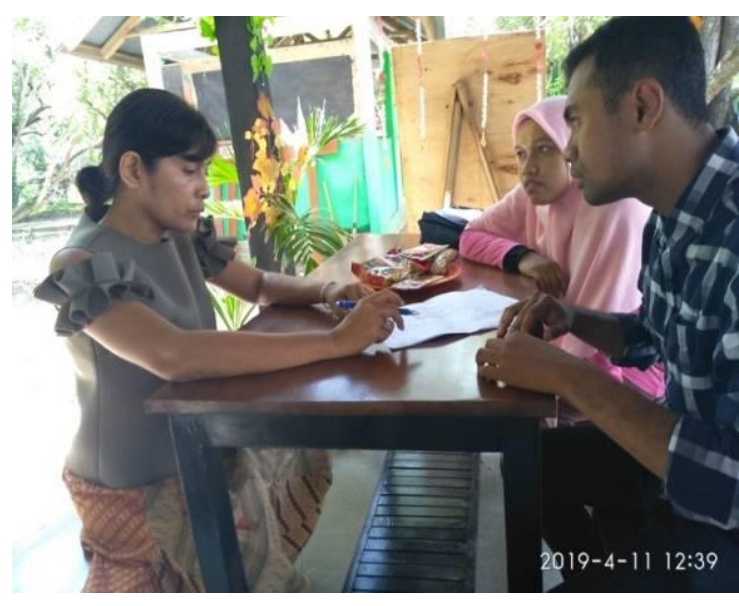

(ii)

Gambar 4. Salah satu surveyor di depan pintu masuk Gua (i) dan surveyor sedang melakukan wawancara dengan salah satu pengelola

\section{Danau Senanggoang}

Danau Senanggoang merupakan danau vulkanik terluas yang berada di Flores, Nusa Tenggara Timur (Mochamad Nur Hadi, Dedi Kusnadi, 2015). Rute jalanan menuju lokasi masih dipenuhi dengan bebatuan yang mengakibatkan kendaraan beroda empat seperti mobil susah untuk lewat. Danau Sano Nggoang merupakan danau vulkanik terluas di Nusa Tenggara Timur, dengan luas sekitar 5.500 hektar, danau ini dianggap sebagai salah satu danau terdalam di dunia yang kedalamannya sekitar 600 meter. Di sepanjang pantai Danau Kawah Sano Nggoang ada beberapa desa tempat tinggal penduduk setempat. Desa-desa pertanian kecil ini hanya menampung 250 penduduk yang tinggal di rumah bambu anyaman tradisional atau rumah kayu atau bata yang lebih modern. Fasilitas di danau senanggoang masih sangat minim selain itu akses menuju lokasi ini juga sulit karena jalanan yang masih berbatu. Akibatnya beberapa villa atau penginapan yang sudah dibangun tidak pernah digunakan bahkan ada bangunan villa yang sudah rubuh. 


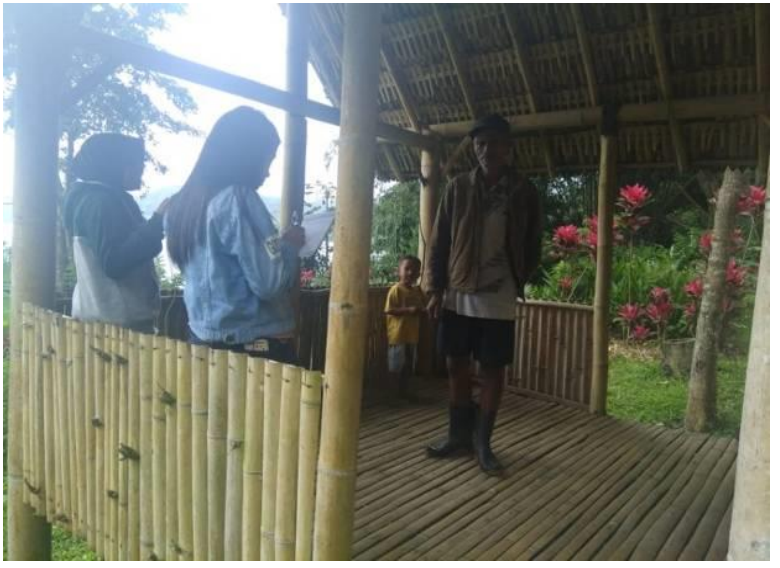

(i)

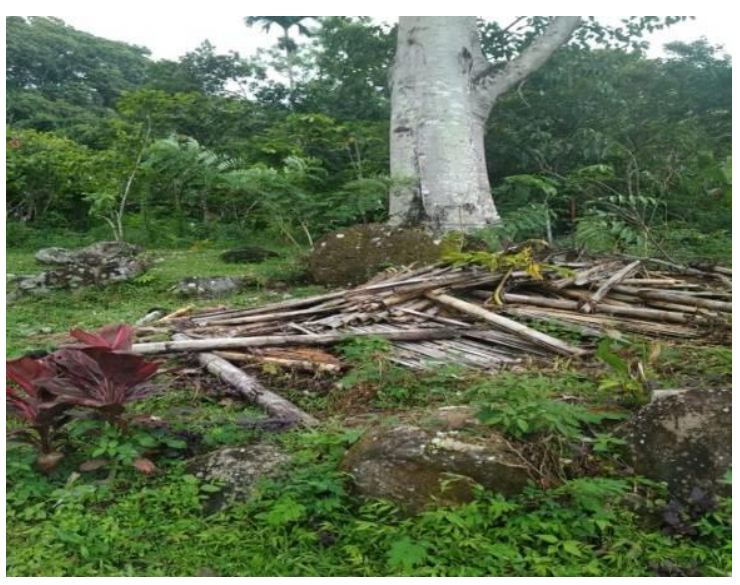

(ii)

Gambar 5. Surveyor sedang berdiskusi dengan salah seorang penduduk lokal (i), Salah satu lokasi penginapan sekitar danau yang telah dibongkar

\section{Kampung Tado}

Kampung Tado berada tidak jauh dari Daerah Aliran Sungai (DAS) Wae Impor yang menyimpan berbagai keunikan alam. Tado merupakan sebuah kampung tradisional dalam bilangan Desa Nampar Macing, Kecamatan Sano Nggoang. Kampung Tado dapat dijangkau dengan kendaraan jalan darat dari Labuan Bajo, ibu kota Kabupaten Manggarai Barat dengan jarak tempuh sekitar 90 menit atau dari Ruteng, ibu kota Kabupaten Manggarai sekitar 120 menit. Mengingat kampung ini merupakan destinasi baru, belum tersedia fasilitas penunjang yang memadai di daerah ini. Di desa ini terdapat pokdarwis yang digerakkan oleh pemuda setempat, mereka juga diberdayakan oleh salah satu LSM dari jakarta sampai sekarang pokdarwis ini masih hidup. Terdapat sebuah mini cafe yang juga berfungsi sebagai pusat informasi wisata di kampung Tado, mini cafe ini juga menyediakan fasilitas penginapan bagi tamu yang mau menginap.

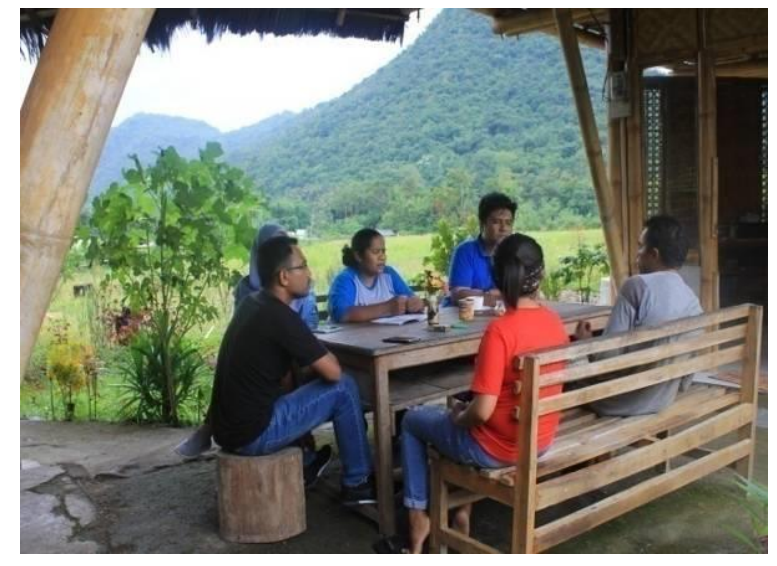

(i)

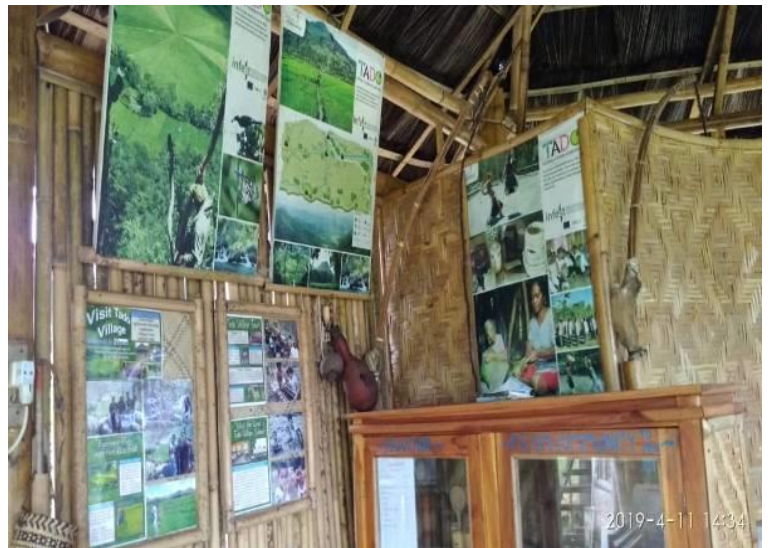

(ii)

Gambar 6. Berdiskusi dengan salah satu pengelola wisata di kampung Tado (i), Papan Informasi Wisata yang ada di kampung Tado (ii)

\section{Desa adat Melo}

Kampung adat Melo atau desa adat melo adalah desa yang tidak jauh dari Labuan Bajo, dibutuhkan waktu sekitar 40 menit untuk mencapai lokasi desa adati dari pusat Kota Labuan Bajo. Lokasinya mudah diakses dari jalan utama Trans Flores yang kondisi jalan rayanya sangat baik. Desa dengan penduduk sekitar 1.800 orang ini memiliki udara yang sejuk. suhu tertinggi di desa ini mencapai 20 Celcius saja. Kampung adat Mel memiliki sanggar tari yang sering menjamu para tamu dari luar negeri. Sayang sekali kenakaran di tempat sanggar dan juga 
tempat pertunjukkan menyebabkan beberapa fasilitas dan artefak peninggalan sejarah rusak dan tidak bisa digunakan lagi. Pengelola sanggar setempat telah mengajukan permohonan bantuan revitalisasi kepada beberapa pihak dan sejauh ini baru ada bantuan dari salah satu BUMN yang merenovasi rumah penyimpanan barang-barang adat dan fasilitas toilet. Karena letaknya di ketinggian, pemandangan dari desa Melo sangat indah. Di desa ini juga terdapat peninggalan batu kuno semacam menhir yang tersebar disekitar area sanggar. Menurut penuturan pengelola lokasi sekitar memang sudah turun temurun selama ratusan tahun digunakan untuk beberapa ritual adat, salah satunya penyambutan tamu asing yang mau berkunjung atau masuk ke desa.

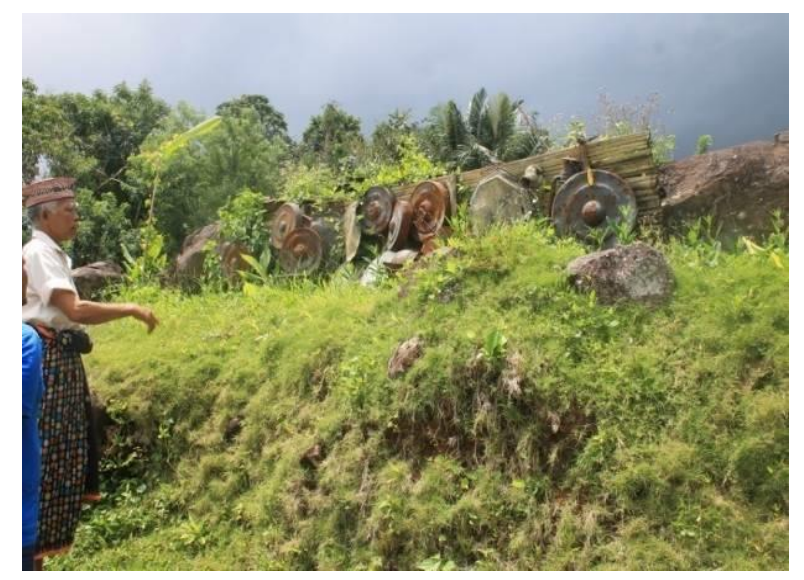

(i)

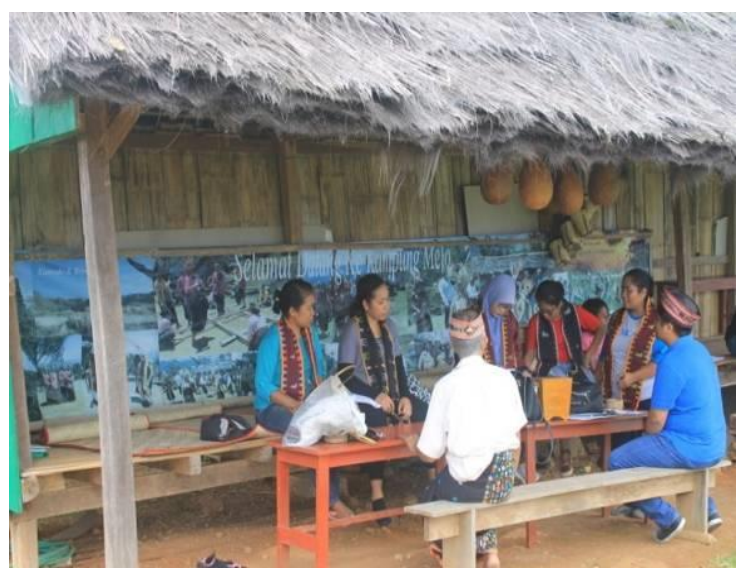

(ii)

Gambar 7. Peralatan adat yang terbakar dan tidak bisa digunakan lagi (i), Berdiskusi dengan salah satu pengelola wisata di kampung Melo (ii)

Hasil survey di 7 lokasi destinasi wisata ditampilkan pada tabel berikut :

Tabel 1. Kriteria Standar Usaha Wisata

\begin{tabular}{|c|c|c|c|c|c|c|c|c|c|}
\hline \multirow[b]{2}{*}{ Aspek } & \multirow[b]{2}{*}{ Unsur } & \multirow[b]{2}{*}{ Sub Unsur } & \multicolumn{7}{|c|}{ Destinasi } \\
\hline & & & $\begin{array}{c}\text { Komo } \\
\text { do }\end{array}$ & Padar & $\begin{array}{c}\text { Gua } \\
\text { rang } \\
\text { ko }\end{array}$ & $\begin{array}{c}\text { Danau } \\
\text { Senanggoa } \\
\text { ng }\end{array}$ & $\begin{array}{l}\text { Desa } \\
\text { Tado }\end{array}$ & $\begin{array}{c}\text { Kamp } \\
\text { ung } \\
\text { Melo }\end{array}$ & $\begin{array}{c}\text { Gua } \\
\text { Batu } \\
\text { Cerm } \\
\text { in }\end{array}$ \\
\hline \multirow[t]{4}{*}{ Produk } & $\begin{array}{l}\text { Petunjuk } \\
\text { Arah }\end{array}$ & $\begin{array}{l}\text { Papan nama } \\
\text { objek wisata }\end{array}$ & $\sqrt{ }$ & $\sqrt{ }$ & $\sqrt{ }$ & $\sqrt{ }$ & $\sqrt{ }$ & $\sqrt{ }$ & $\sqrt{ }$ \\
\hline & & $\begin{array}{l}\text { Tanda arah } \\
\text { objek wisata }\end{array}$ & $\sqrt{ }$ & $\sqrt{ }$ & $\sqrt{ }$ & $\sqrt{ }$ & $\sqrt{ }$ & $\sqrt{ }$ & $\sqrt{ }$ \\
\hline & Parkir & $\begin{array}{l}\text { Tersedia } \\
\text { tempat parkir } \\
\text { yang luas dan } \\
\text { pengaturan } \\
\text { lalu lintasnya }\end{array}$ & $\sqrt{ }$ & $\mathrm{X}$ & $\mathrm{X}$ & $\sqrt{ }$ & $\mathrm{X}$ & $\mathrm{X}$ & $\sqrt{ }$ \\
\hline & $\begin{array}{l}\text { Lobby } \\
\text { Center }\end{array}$ & $\begin{array}{l}\text { Tersedia } \\
\text { lobby dengan } \\
\text { sirkulasi } \\
\text { udara dan } \\
\text { pencahayaan } \\
\text { yang baik }\end{array}$ & $\sqrt{ }$ & $\sqrt{ }$ & $X$ & $\mathrm{X}$ & $\sqrt{ }$ & $\sqrt{ }$ & $\sqrt{ }$ \\
\hline
\end{tabular}




\begin{tabular}{|c|c|c|c|c|c|c|c|c|c|}
\hline \multirow[b]{2}{*}{ Aspek } & \multirow[b]{2}{*}{ Unsur } & \multirow[b]{2}{*}{ Sub Unsur } & \multicolumn{7}{|c|}{ Destinasi } \\
\hline & & & $\begin{array}{c}\text { Komo } \\
\text { do }\end{array}$ & Padar & $\begin{array}{c}\text { Gua } \\
\text { rang } \\
\text { ko }\end{array}$ & $\begin{array}{c}\text { Danau } \\
\text { Senanggoa } \\
\text { ng }\end{array}$ & $\begin{array}{l}\text { Desa } \\
\text { Tado }\end{array}$ & $\begin{array}{c}\text { Kamp } \\
\text { ung } \\
\text { Melo }\end{array}$ & $\begin{array}{c}\text { Gua } \\
\text { Batu } \\
\text { Cerm } \\
\text { in }\end{array}$ \\
\hline & $\begin{array}{l}\text { Area } \\
\text { Belanja }\end{array}$ & $\begin{array}{l}\text { Tersedia } \\
\text { minimarket } \\
\text { dan souvenir } \\
\text { shop }\end{array}$ & $\sqrt{ }$ & $\sqrt{ }$ & $\mathrm{X}$ & $\mathrm{X}$ & $\sqrt{ }$ & $\mathrm{X}$ & $\sqrt{ }$ \\
\hline & $\begin{array}{l}\text { Toilet } \\
\text { Umum }\end{array}$ & $\begin{array}{l}\text { Toilet wanita } \\
\text { dan pria } \\
\text { terpisah }\end{array}$ & $\sqrt{ }$ & $\sqrt{ }$ & $\mathrm{X}$ & $\mathrm{X}$ & $\sqrt{ }$ & $\sqrt{ }$ & $\sqrt{ }$ \\
\hline & & $\begin{array}{l}\text { Toilet bagi } \\
\text { pengunjung } \\
\text { dengan } \\
\text { keterbatasan } \\
\text { fisik }\end{array}$ & $\sqrt{ }$ & $\sqrt{ }$ & $\mathrm{X}$ & $\mathrm{X}$ & $\mathrm{X}$ & $\sqrt{ }$ & $\mathrm{X}$ \\
\hline & & $\begin{array}{l}\text { Alat } \\
\text { pengering } \\
\text { tangan }\end{array}$ & $\sqrt{ }$ & $\mathrm{X}$ & $\mathrm{X}$ & $\mathrm{X}$ & $\sqrt{ }$ & $\mathrm{X}$ & $\sqrt{ }$ \\
\hline & $\begin{array}{l}\text { Ruang } \\
\text { pengoba } \\
\text { tan }\end{array}$ & $\begin{array}{l}\text { Tersedia } \\
\text { ruang } \\
\text { pengobatan } \\
\text { dan peralatan } \\
\text { medis }\end{array}$ & $\sqrt{ }$ & $\mathrm{X}$ & $\mathrm{X}$ & $\mathrm{X}$ & $\sqrt{ }$ & $\mathrm{X}$ & $\sqrt{ }$ \\
\hline & & Kursi roda & $\sqrt{ }$ & $\mathrm{X}$ & $\mathrm{X}$ & $\mathrm{X}$ & $\sqrt{ }$ & $\mathrm{X}$ & $\mathrm{X}$ \\
\hline & & $\begin{array}{l}\text { Tempat tidur } \\
\text { pasien }\end{array}$ & $\sqrt{ }$ & $\mathrm{X}$ & $\mathrm{X}$ & $\mathrm{X}$ & $\sqrt{ }$ & $\mathrm{X}$ & $\sqrt{ }$ \\
\hline & Kantor & $\begin{array}{l}\text { Tersedia } \\
\text { ruang } \\
\text { pimpinan }\end{array}$ & $\sqrt{ }$ & $\mathrm{X}$ & $\mathrm{X}$ & $\mathrm{X}$ & $\sqrt{ }$ & $\mathrm{X}$ & $\sqrt{ }$ \\
\hline & & Pemasaran & $\sqrt{ }$ & $\mathrm{X}$ & $\mathrm{X}$ & $\mathrm{X}$ & $\sqrt{ }$ & $\mathrm{X}$ & $\sqrt{ }$ \\
\hline & & Front office & $\sqrt{ }$ & $\mathrm{X}$ & $\sqrt{ }$ & $\mathrm{X}$ & $\sqrt{ }$ & $\mathrm{X}$ & $\sqrt{ }$ \\
\hline & & $\begin{array}{l}\text { Food dan } \\
\text { beverage }\end{array}$ & $\sqrt{ }$ & $\mathrm{X}$ & $\sqrt{ }$ & $\mathrm{X}$ & $\sqrt{ }$ & $\mathrm{X}$ & $\sqrt{ }$ \\
\hline & & Tata graha & $\sqrt{ }$ & $\mathrm{X}$ & $\mathrm{X}$ & $\mathrm{X}$ & $\sqrt{ }$ & $\mathrm{X}$ & $\sqrt{ }$ \\
\hline & & Engineering & $\sqrt{ }$ & $\mathrm{X}$ & $\mathrm{X}$ & $\mathrm{X}$ & $\sqrt{ }$ & $\mathrm{X}$ & $\sqrt{ }$ \\
\hline & & Personalia & $\sqrt{ }$ & $\mathrm{X}$ & $\mathrm{X}$ & $\mathrm{X}$ & $\sqrt{ }$ & $\mathrm{X}$ & $\sqrt{ }$ \\
\hline & & $\begin{array}{l}\text { Administrasi } \\
\text { dan keuangan }\end{array}$ & $\sqrt{ }$ & $\sqrt{ }$ & $\mathrm{X}$ & $\mathrm{X}$ & $\sqrt{ }$ & $\sqrt{ }$ & $\sqrt{ }$ \\
\hline & $\begin{array}{l}\text { Keaman } \\
\text { an }\end{array}$ & $\begin{array}{l}\text { Ruang } \\
\text { security }\end{array}$ & $\sqrt{ }$ & $\sqrt{ }$ & $\sqrt{ }$ & $\mathrm{X}$ & $\sqrt{ }$ & $\mathrm{X}$ & $\sqrt{ }$ \\
\hline & & Ruang CCTV & $\sqrt{ }$ & $\mathrm{X}$ & $\mathrm{X}$ & $\mathrm{X}$ & $\mathrm{X}$ & $\mathrm{X}$ & $\mathrm{X}$ \\
\hline
\end{tabular}




\begin{tabular}{|c|c|c|c|c|c|c|c|c|c|}
\hline \multirow[b]{2}{*}{ Aspek } & \multirow[b]{2}{*}{ Unsur } & \multirow[b]{2}{*}{ Sub Unsur } & \multicolumn{7}{|c|}{ Destinasi } \\
\hline & & & $\begin{array}{c}\text { Komo } \\
\text { do }\end{array}$ & Padar & $\begin{array}{c}\text { Gua } \\
\text { rang } \\
\text { ko }\end{array}$ & $\begin{array}{c}\text { Danau } \\
\text { Senanggoa } \\
\text { ng }\end{array}$ & $\begin{array}{l}\text { Desa } \\
\text { Tado }\end{array}$ & $\begin{array}{c}\text { Kamp } \\
\text { ung } \\
\text { Melo }\end{array}$ & $\begin{array}{c}\text { Gua } \\
\text { Batu } \\
\text { Cerm } \\
\text { in }\end{array}$ \\
\hline & Utilitas & $\begin{array}{l}\text { Tersedia } \\
\text { instalasi } \\
\text { listrik }\end{array}$ & $\sqrt{ }$ & $\mathrm{X}$ & $\mathrm{X}$ & $\sqrt{ }$ & $\sqrt{ }$ & $\sqrt{ }$ & $\mathrm{X}$ \\
\hline & & $\begin{array}{l}\text { Tersedia } \\
\text { instalasi air } \\
\text { bersih }\end{array}$ & $\sqrt{ }$ & $\mathrm{X}$ & $\mathrm{X}$ & $\mathrm{X}$ & $\mathrm{X}$ & $\sqrt{ }$ & $\sqrt{ }$ \\
\hline & & $\begin{array}{l}\text { Tersedia } \\
\text { genset }\end{array}$ & $\sqrt{ }$ & $\mathrm{X}$ & $\mathrm{X}$ & $\sqrt{ }$ & $\sqrt{ }$ & $\mathrm{X}$ & $\mathrm{X}$ \\
\hline & & $\begin{array}{l}\text { Tersedia } \\
\text { instalasi } \\
\text { jaringan } \\
\text { komunikasi }\end{array}$ & $\sqrt{ }$ & $\sqrt{ }$ & $\sqrt{ }$ & $\mathrm{X}$ & $\sqrt{ }$ & $\sqrt{ }$ & $\sqrt{ }$ \\
\hline & $\begin{array}{l}\text { Pengelol } \\
\text { aan } \\
\text { Limbah }\end{array}$ & $\begin{array}{l}\text { Tempat } \\
\text { penampunga } \\
\text { n sampah } \\
\text { sementara } \\
\text { yang tertutup } \\
\text { dan terpisah } \\
\text { antara } \\
\text { sampah } \\
\text { kering dan } \\
\text { basah }\end{array}$ & $\sqrt{ }$ & $\sqrt{ }$ & $\mathrm{X}$ & $\mathrm{X}$ & $\sqrt{ }$ & $\sqrt{ }$ & $\sqrt{ }$ \\
\hline & & $\begin{array}{l}\text { Pengelolaan } \\
\text { limbah }\end{array}$ & $\mathrm{X}$ & $\mathrm{X}$ & $\mathrm{X}$ & $\mathrm{X}$ & $\sqrt{ }$ & $\mathrm{X}$ & $\mathrm{X}$ \\
\hline \multirow[t]{4}{*}{$\begin{array}{l}\text { Pelaya } \\
\text { nan }\end{array}$} & $\begin{array}{l}\text { Kantor } \\
\text { depan }\end{array}$ & $\begin{array}{l}\text { Penanganan } \\
\text { proses tiket } \\
\text { dan informasi }\end{array}$ & $\sqrt{ }$ & $\sqrt{ }$ & $\mathrm{X}$ & $\mathrm{X}$ & $\sqrt{ }$ & $\mathrm{X}$ & $\sqrt{ }$ \\
\hline & & $\begin{array}{l}\text { Pelayanan } \\
\text { khusus untuk } \\
\text { pengunjung } \\
\text { dengan } \\
\text { keterbatasan } \\
\text { fisik }\end{array}$ & $\sqrt{ }$ & $\mathrm{X}$ & $\mathrm{X}$ & $\mathrm{X}$ & $\sqrt{ }$ & $\mathrm{X}$ & $\sqrt{ }$ \\
\hline & $\begin{array}{l}\text { Restaura } \\
\text { nt }\end{array}$ & $\begin{array}{l}\text { Tersedia } \\
\text { pelayanan } \\
\text { penyajian } \\
\text { makanan dan } \\
\text { minuman }\end{array}$ & $\sqrt{ }$ & $\mathrm{X}$ & $\sqrt{ }$ & $\mathrm{X}$ & $\sqrt{ }$ & $\mathrm{X}$ & $\sqrt{ }$ \\
\hline & & $\begin{array}{l}\text { Pelayanan } \\
\text { khusus untuk } \\
\text { pengunjung } \\
\text { dengan } \\
\text { keterbatasan }\end{array}$ & $\sqrt{ }$ & $\mathrm{X}$ & $\mathrm{X}$ & $\mathrm{X}$ & $\sqrt{ }$ & $\mathrm{X}$ & $\sqrt{ }$ \\
\hline
\end{tabular}




\begin{tabular}{|c|c|c|c|c|c|c|c|c|c|}
\hline \multirow[b]{2}{*}{ Aspek } & \multirow[b]{2}{*}{ Unsur } & \multirow[b]{2}{*}{ Sub Unsur } & \multicolumn{7}{|c|}{ Destinasi } \\
\hline & & & $\begin{array}{c}\text { Komo } \\
\text { do }\end{array}$ & Padar & $\begin{array}{c}\text { Gua } \\
\text { rang } \\
\text { ko }\end{array}$ & $\begin{array}{c}\text { Danau } \\
\text { Senanggoa } \\
\text { ng }\end{array}$ & $\begin{array}{l}\text { Desa } \\
\text { Tado }\end{array}$ & $\begin{array}{c}\text { Kamp } \\
\text { ung } \\
\text { Melo }\end{array}$ & $\begin{array}{c}\text { Gua } \\
\text { Batu } \\
\text { Cerm } \\
\text { in }\end{array}$ \\
\hline & & fisik & & & & & & & \\
\hline & $\begin{array}{l}\text { Keaman } \\
\text { an }\end{array}$ & $\begin{array}{l}\text { Pemadam } \\
\text { kebakaran }\end{array}$ & $\sqrt{ }$ & $\mathrm{X}$ & $\mathrm{X}$ & $\mathrm{X}$ & $\sqrt{ }$ & $\mathrm{X}$ & $\sqrt{ }$ \\
\hline & & Asuransi & $\sqrt{ }$ & $\mathrm{X}$ & $\mathrm{X}$ & $\mathrm{X}$ & $\sqrt{ }$ & $\mathrm{X}$ & $\mathrm{X}$ \\
\hline & & Jalur evakuasi & $\sqrt{ }$ & $\mathrm{X}$ & $\mathrm{X}$ & $\mathrm{X}$ & $\sqrt{ }$ & $\mathrm{X}$ & $\sqrt{ }$ \\
\hline & Kesehat & Ruang P3K & $\sqrt{ }$ & $\mathrm{X}$ & $\mathrm{X}$ & $\mathrm{X}$ & $\sqrt{ }$ & $\mathrm{X}$ & $\sqrt{ }$ \\
\hline & & $\begin{array}{l}\text { Tenaga medis } \\
\text { dan tenaga } \\
\text { SDM } \\
\text { bersertifikat }\end{array}$ & $\sqrt{ }$ & $\mathrm{X}$ & $\mathrm{X}$ & $\sqrt{ }$ & $\sqrt{ }$ & $\mathrm{X}$ & $\sqrt{ }$ \\
\hline \multirow[t]{7}{*}{$\begin{array}{l}\text { Pengel } \\
\text { olaan }\end{array}$} & $\begin{array}{l}\text { Organisa } \\
\text { si }\end{array}$ & $\begin{array}{l}\text { Memiliki } \\
\text { manajemen }\end{array}$ & $\sqrt{ }$ & $\sqrt{ }$ & $\sqrt{ }$ & $\mathrm{x}$ & $\sqrt{ }$ & $\mathrm{X}$ & $\sqrt{ }$ \\
\hline & & $\begin{array}{l}\text { Memiliki } \\
\text { manajemen } \\
\text { penjamin } \\
\text { mutu }\end{array}$ & $\sqrt{ }$ & $\sqrt{ }$ & $\mathrm{X}$ & $\mathrm{X}$ & $\sqrt{ }$ & $\mathrm{X}$ & $\sqrt{ }$ \\
\hline & & $\begin{array}{l}\text { Memiliki } \\
\text { rencana } \\
\text { strategis } \\
\text { usaha }\end{array}$ & $\sqrt{ }$ & $\sqrt{ }$ & $\mathrm{X}$ & $\mathrm{X}$ & $\sqrt{ }$ & $\mathrm{X}$ & $\sqrt{ }$ \\
\hline & & $\begin{array}{l}\text { Memiliki } \\
\text { program } \\
\text { pengembanga } \\
\text { n produk }\end{array}$ & $\sqrt{ }$ & $\mathrm{X}$ & $\mathrm{X}$ & $\mathrm{X}$ & $\sqrt{ }$ & $\mathrm{X}$ & $\sqrt{ }$ \\
\hline & $\begin{array}{l}\text { Kemitra } \\
\text { an dan } \\
\text { penggun } \\
\text { aan }\end{array}$ & $\begin{array}{l}\text { Memiliki } \\
\text { program } \\
\text { kemitraan } \\
\text { dengan usaha } \\
\text { mikro, kecil, } \\
\text { dan } \\
\text { menengah }\end{array}$ & $\sqrt{ }$ & $\mathrm{X}$ & $\mathrm{X}$ & $\mathrm{X}$ & $\sqrt{ }$ & $\mathrm{X}$ & $\sqrt{ }$ \\
\hline & & $\begin{array}{l}\text { Memiliki } \\
\text { program } \\
\text { tanggung } \\
\text { jawab sosial } \\
\text { perusahaan }\end{array}$ & $\sqrt{ }$ & $\mathrm{X}$ & $\mathrm{X}$ & $\mathrm{X}$ & $\sqrt{ }$ & $\mathrm{X}$ & $\mathrm{X}$ \\
\hline & $\begin{array}{l}\text { Sumber } \\
\text { Daya } \\
\text { Manusia }\end{array}$ & $\begin{array}{l}\text { Melaksanaka } \\
\text { n program } \\
\text { sertifikasi } \\
\text { kompetensi }\end{array}$ & $\sqrt{ }$ & $\mathrm{X}$ & $\mathrm{X}$ & $\mathrm{X}$ & $\sqrt{ }$ & $\mathrm{x}$ & $\sqrt{ }$ \\
\hline
\end{tabular}




\begin{tabular}{|c|c|c|c|c|c|c|c|c|c|}
\hline \multirow[b]{2}{*}{ Aspek } & \multirow[b]{2}{*}{ Unsur } & \multirow[b]{2}{*}{ Sub Unsur } & \multicolumn{7}{|c|}{ Destinasi } \\
\hline & & & $\begin{array}{c}\text { Komo } \\
\text { do }\end{array}$ & Padar & $\begin{array}{c}\text { Gua } \\
\text { rang } \\
\text { ko }\end{array}$ & $\begin{array}{c}\text { Danau } \\
\text { Senanggoa } \\
\text { ng }\end{array}$ & $\begin{array}{l}\text { Desa } \\
\text { Tado }\end{array}$ & $\begin{array}{c}\text { Kamp } \\
\text { ung } \\
\text { Melo }\end{array}$ & $\begin{array}{c}\text { Gua } \\
\text { Batu } \\
\text { Cerm } \\
\text { in }\end{array}$ \\
\hline & & karyawan & & & & & & & \\
\hline & & $\begin{array}{l}\text { Karyawan } \\
\text { mampu } \\
\text { berbahasa } \\
\text { asing minimal } \\
\text { bahasa } \\
\text { Inggris }\end{array}$ & $\sqrt{ }$ & $\sqrt{ }$ & $\mathrm{X}$ & $\mathrm{X}$ & $\sqrt{ }$ & $\mathrm{X}$ & $\sqrt{ }$ \\
\hline & & $\begin{array}{l}\text { Melaksanaka } \\
\text { n penilaian } \\
\text { kinerja SDM }\end{array}$ & $\sqrt{ }$ & $\sqrt{ }$ & $\mathrm{X}$ & $\mathrm{X}$ & $\sqrt{ }$ & $\mathrm{X}$ & $\sqrt{ }$ \\
\hline
\end{tabular}

\section{SIMPULAN DAN TINDAK LANJUT}

Berdasarkan hasil survey yang telah dilakukan oleh Tim Pengabdian Universitas Flores, maka dapat disimpulkan bahwa belum terpenuhi beberapa fasilitas standar di 7 destinasi wisata (Danau Senanggoang, Kampung Tado, Kampung Melo, Gua Batu Cermin, Gua Rangko, Pulau Komodo, Pulau Padar). Fasilitas yang ada juga tidak terawat sehingga menimbulkan ketidaknyamanan pengunjung bahkan di kampung Melo semua peralatan adat untuk penyambutan tamu yang pernah terbakar habis belum mendapat ganti. Fasilitas toilet kurang terawat sedangkan aktivitas kunjungan di pulau ini cukup ramai. Akses jalan menuju danau Senanggoang juga tidak begitu baik dan semua penginapan yang ada telah ditutup karena minimnya kunjungan.

Dari hasil kegiatan survey yang dilakukan dapat disarankan agar Pemerintah Kabupaten dan pengelola destinasi wisata di Kabupaten Manggarai Barat bekerja sama dalam pengadaan fasilitas dan memelihara fasilitas yang telah ada, sehingga objek pariwisata di 7 lokasi tersebut menjadi semakin tertata dan maju. Selain itu perlu dilakukan perbaikan-perbaikan pada fasilitas sarana maupun prasrana yang mengalami banyak kerusakan seperti di kampung Melo dan Gua Batu Cermin. Agar semakin tinggi nilai penggunaan fasilitas serta termanfaatkan dengan baik demi kemajuan pariwisata di kabupaten Manggarai Barat.

\section{DAFTAR RUJUKAN}

Indayani, N., \& Dewi, S. (2018). Strategi Pengembangan Objek Wisata Gua Batu Cermin Ditinjau dari Aspek Lingkungan Geografis di Kecamatan Komodo Kabupaten Manggarai Barat. Geodika: Jurnal Kajian Ilmu Dan Pendidikan Geografi, 2(1), 22. https://doi.org/10.29408/geodika.v2i1.870

Mochamad Nur Hadi, Dedi Kusnadi, R. S. L. S. (2015). SURVEI GEOLOGI DAN GEOKIMIA PANAS BUMI DAERAH WAESANO, KABUPATEN MANGGARAI BARAT, PROVINSI NUSA TENGGARA TIMUR. In Pusat Sumber daya Mineral Batu Bara dan panas Bumi (Vol. 7, Issue 2).

Rachim, H. A., \& Ginting, P. A. (2019). Pemberdayaan Masyarakat Di Desa Pota Wangka Labuan Bajo Melalui Program Peduli Lingkungan ( Sekolah Lingkungan) Dengan Metode Partisipatory Learning and Action. Prosiding Penelitian Dan Pengabdian Kepada Masyarakat, 6(1), 46. https://doi.org/10.24198/jppm.v6i1.22785 
Remmer, S. (2017). Tourism impacts in Labuan Bajo. https://www.swisscontact.org/fileadmin/user_upload/HEAD_OFFICE/Pictures/Tourismu s_Landing_page/Labuan_Bajo_Impact_Assessment.pdf

Rufalzyh. (2017). Strategi Komunikasi Pemasaran Pariwisata Labuan Bajo oleh Dinas Pariwisata dan Kebudayaan Kabupaten Manggarai Barat NTT. Skripsi Fakultas Psikologi dan Ilmu Budaya.

Suasapha, A., Wiarti, L., Mertha, I., Widana, I. B. G. ., Dianasari, L., \& Tirtawati, M. (2020). Intradestination Movement of Tourist Visiting Labuan Bajo In East Nusa Tenggara Indonesia. Padjadjaran Communication Conference Series, March. https://doi.org/10.4108/eai.9-10-2019.2291143

Mustari, A.H., Siga, H.R., Noviandi, T., Ayatulah, A. \& Zainudin, Z. (2016). Kajıan Ekologı Dan Status Keberadaan Komodo (Varanus Komodoensis) Di Pulau Padar Taman Nasional Komodo. Media Konservasi. 15, 1 DOI:https://doi.org/10.29244/medkon.15.1.\%p.

Yusni Wiarti, L., Ayu Made Lily Dianasari, D., Bagus Putra Negarayana, I., \& Hery Suasapha, A. (2017). Labuan Bajo: A Quality Tourist Destination in Indonesia? An Exploratory Study on Tourists Perspectives. Conference Proceeding ISBN Number 978-3-033-06515-4. www.beritasatu.com 